\title{
Sleep-disordered breathing and preeclampsia
}

\author{
Jyotsna Suri', J.C. Suri ${ }^{2}$
}

1 Senior Specialist and Associate Professor, Department of Obstetrics and Gynaecology, Vardhman Mahavir Medical College and Safdarjung Hospital, New Delhi 110029, India

2 Professor and Consultant, Professor and Consultant, Head of Department of Pulmonary, Critical Care and Sleep Medicine, Vardhman Mahavir Medical Collegeand Safdarjung Hospital, New Delhi 110029, India

\begin{abstract}
Preeclampsia is a common cause of maternal and fetal morbidity. Endothelial dysfunction(ED) is the most important pathophysiologic mechanism for preeclampsia.Sleep-disordered breathing (SDB) is an important underlying mechanismin cardiovascular complications such as hypertension and ischemic heart disease with ED. Physiological changes during pregnancy predisposewomen to increased prevalence of SDB during the third trimester of pregnancy. SDB is seen more often in preeclampsia and ED is seen in preeclampsia and SDB. ED in preeclampsia may be potentiated by SDB. SDB appears to contribute significantly to the severity of ED in preeclampsia leading to more severe maternal and fetal outcomes. Continuous positive airway pressure (CPAP) treatment has shown benefit in reducing the severity of preeclampsia and improving the maternal and fetal outcomes in some studies. Further research is warranted in this area, especially to study the impact of CPAP on the severity of preeclampsia.

Keywords: Gestational hypertension, Preeclampsia, Sleep Disordered Breathing, Maternal outcome, Fetal outcome
\end{abstract}

$\mathrm{P}$ reeclampsia is a hypertensive disorder unique to pregnancy, which is characterized by hypertension, proteinuria, and edema. It affects about 7\%-10\% of all pregnant women and has a predilection for primigravidas ${ }^{1}$. It is diagnosed by a new-onset hypertension of $>140 / 90 \mathrm{~mm} \mathrm{Hg}$ after 20 weeks of gestation, along with proteinuria of $0.3 \mathrm{~g}$ in a $24 \mathrm{~h}$ urine specimen or a dipstick value of $>1+$ if quantitative measurement is not available. ${ }^{1}$ In patients with new-onset

\section{Address for correspondence:}

\section{Dr Jyotsna Suri}

Senior Specialist and Associate Professor, Department of Obstetrics and Gynaecology,

Vardhman Mahavir Medical College and Safdarjung Hospital, New Delhi 110029 , India D-II/153, West Kidwai Nagar, New Delhi Email: jyotsnasuri@gmail.com hypertension without proteinuria, the new onset of the following features is also diagnostic of preeclampsia: platelet count $<1 \mathrm{lac} / \mathrm{ml}$, serum creatinine $>1.1 \mathrm{mg} / \mathrm{dl}$, liver transaminases more than double the normal, pulmonary edema, and cerebral or visual symptoms. Gestational hypertension, but without proteinuria, is also a newonset hypertensive disorder of pregnancy that can develop into preeclampsia during the course of pregnancy ${ }^{2}$.

Preeclampsia is one of the leading causes of maternal morbidity and mortality, ICU admissions, and neonatal morbidity ${ }^{2,3}$. The adverse maternal outcomes include placental abruption, seizures, stroke, renal failure, liver dysfunction, cardiac dysfunction, and pulmonary edema. Patients with preeclampsia are also at risk of developing coronary artery disease and stroke later in life ${ }^{4}$. The notable adverse fetal outcomes include preterm birth, intrauterine growth restriction, still birth, low APGAR 
at birth, and prolonged nursery stay ${ }^{5,6}$.

The exact pathogenesis of the hypertensive disorders is not certain; however most research points toward the central role of placenta, as placenta is necessary for the development of preeclampsia and not the fetus.Besides, the definitive treatment of preeclampsia is delivery. It is postulated that defective trophoblastic invasion or differentiation results in production of reactive oxygen species and other inflammatory mediators, which ultimately leads to endothelial dysfunction (ED) affecting all the systems of the body ${ }^{7}$ (Fig 1).

Sleep-disordered breathing (SDB) is a spectrum of disorders ranging from the mildest form of upper airway resistance syndrome to the most severe form of obesity hypoventilation syndrome ${ }^{8}$. The pathogenesis of SDB may be related to anatomical factors, such as craniofacial abnormalities or mechanical obstruction of the airway, leading to small pharyngeal airway or a central ventilatory control disorder".

SDB is associated with several cardiovascular manifestations including hypertension ${ }^{10-14}$. The breathing disturbances are characterized by repeated episodes of partial or complete upper airway obstruction during sleep, which can result in disturbance of normal ventilation, intermittent hypoxemia, and repeated arousals from sleep, leading to increased sympathetic activity even in wakefulstate ${ }^{15}$. These episodes are also associated with oxidative stress, inflammation, and reductions in antioxidant levels. During intermittent hypoxia, the initial response is an increase in the generation of reactive oxygen species. When the generation of reactive oxygen species exceeds antioxidant capacity, oxidative stress can result in $\mathrm{ED}^{16}$. The causation of hypertension in SDB is hence postulated to be due to a combination of increased sympathetic activity and ED (Fig 2).

The physiological and anatomical changes during pregnancy that make a gravid woman more prone to SDB are nasal congestion and rhinitis ${ }^{17}$ (estrogenic effect), edema of the airways (progestogenic effect) ${ }^{17}$, increase in Mallampatiscores ${ }^{18}$, gestational weight gain ${ }^{19}$, and decreased functional residual capacity ${ }^{19}$. Changes in the upper airway patency may also be related to the fluid shifts from the lower limbs to the neck area, as a result of prolonged sitting and recumbency, which is often a feature of pregnancy ${ }^{20}$. The $40 \%$ increase in the blood volume, which occurs in normal pregnancy, makes the fluid shift more remarkable. Some of these changes, such

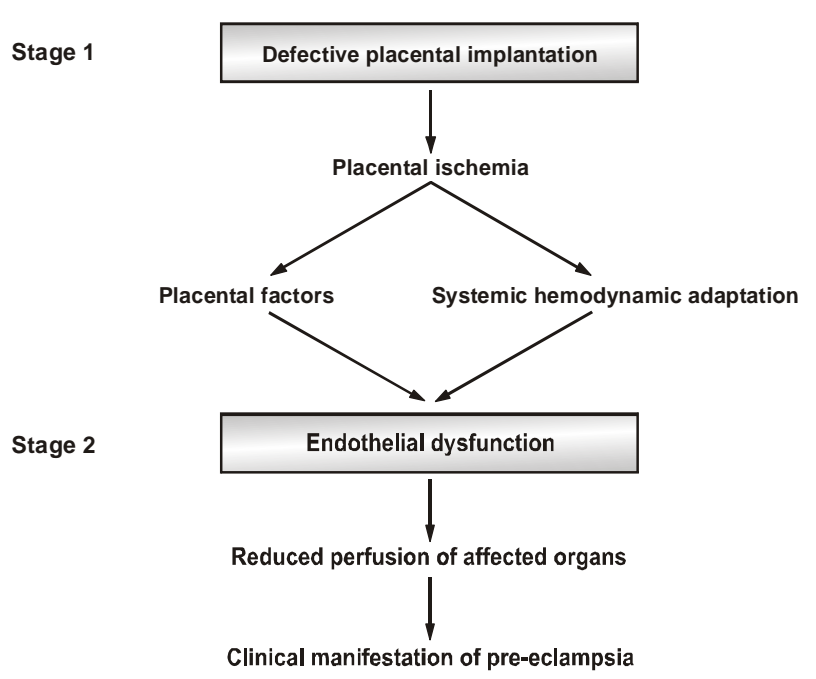

Figure 1: Model for pathogenesis of preeclampsia

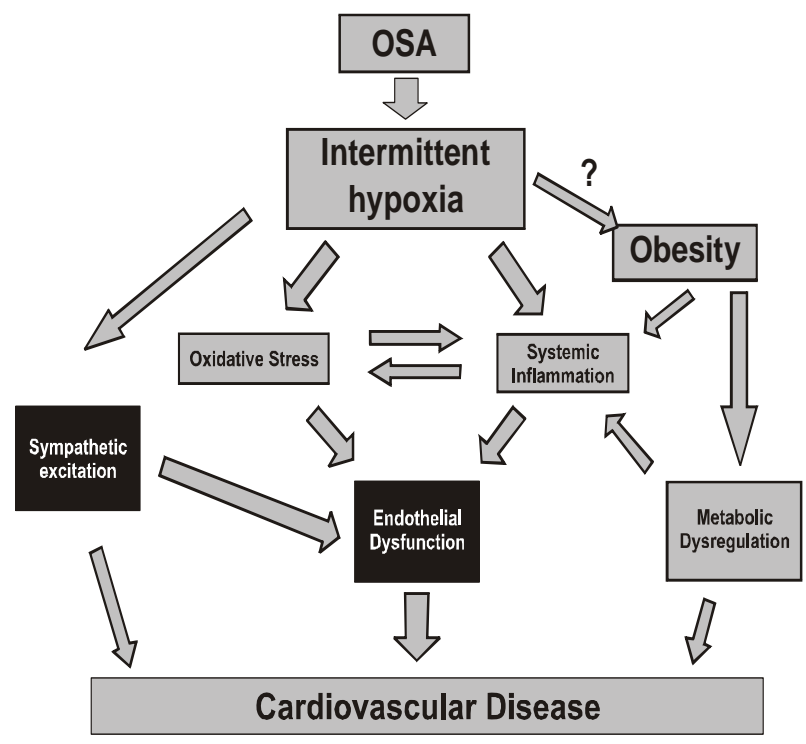

Figure 2: Mechanism of cardiovascular disease in obstructive sleep apnea

as the edema of the airways, are even more pronounced in preeclampsia ${ }^{21}$.

Symptoms of SDB are much more common in pregnant population. Estimates from European and North American studies suggest loud snoring in 14\%-46\% pregnant women ${ }^{22}$. In a study conducted by Suri and colleagues $^{23}$, it was found that snoring occurred in $27.5 \%$ of the 120 pregnant women compared to $7 \%$ of the 100 nonpregnant women $(p=0.00)$. The occurrence of SDB 
in the same group of women was $10.8 \%$ and $1 \%$, respectively $(p=0.146)^{23}$. In another study conducted by the authors, the prevalence of SDB in pregnant women was $9.5 \%$ against theprevalence of $2 \%$ in nonpregnant women $(p=0.05)$. Another interesting observation in this study was that the occurrence of SDB increased with gestational age $(p=0.04)^{24}$. Izciet $\mathrm{al}^{17}$. and Facco et al ${ }^{19}$. also observed an increase in the prevalence of snoring from the first trimester to the third trimester. In a prospective study on 105 pregnant women who underwent polysomnography (PSG) in the first and third trimesters, it was found that the overall prevalence of SDB was $8.4 \%$ and $19.7 \%$ in the first and third trimesters, respectively ${ }^{25}$. The possible association for this increase in snoring and SDB with the gestational age can be explained by the fact that asthe levels of estrogen and progesterone increase with increasing gestation, the physiological changes such as nasal congestion and edema of the airway can get exaggerated, compromising the caliber and patency of the upper airway. Besides this, the mechanical effect of the growing uterus which elevates the diaphragm also plays an important role.

It is possible that, among pregnant women with SDB, intermittent hypoxia leading to abnormal sympathovagal balance and EDmay contribute to the development of new-onset hypertension, that is, preeclampsia, which is also known to be the pathogenic mechanism for preeclampsia, as discussed earlier. Thus, this common possible pathway of the two conditions can explain the strong association of snoring and SDB with pregnancyinduced hypertensiondemonstrated by a growing body of evidence ${ }^{22}$. Both conditions are associated with similar long-term cardiovascular and metabolic consequences. Moreover, both preeclampsia and SDB are more often seen in the third trimester and are associated with poor fetal and maternal outcomes.

Several researchers have corroborated this close association of preeclampsia and SDB. Preeclampsia was seen in $18 \%$ (OR 2.3, CI 1.4-4) of people with snoring and $23 \%$ of those with SDB (OR 2.1, CI 1.1-3.9) by Bourjeily et $\mathrm{a}^{22}$. We too observed that preeclampsia occurred in $30 \%$ patients with snoringcompared to $9 \%$ without snoring $(p=0.004)^{23}$. In a recently published study, Louis et $\mathrm{a}^{21}$. observed that obstructive sleep apnea (OSA) was associated with increased odds of pregnancyrelated morbidities including preeclampsia (OR 2.5, 95\% CI 2.2-2.9) andeclampsia (OR 5.4, 95\% CI 3.3-8.9).
In a study conducted to determine the relationship between snoring, pregnancy-induced hypertension, and intrauterine growth restriction, 502 women completed a questionnaire about snoring and day-time sleepiness and witnessed sleep apnea on the day of delivery. It was found that habitual snoring was independently predictive of hypertension $(\mathrm{OR} 2.03, p<0.05)$ and intrauterine growth restriction $(\mathrm{OR} 3.45, p<0.01)$, in a logistic regression analysis, controlling for weight, age, and smoking ${ }^{26}$.

A meta-analysis of five studies published in 2014 found that in women with SDB the risk of preeclampsia increased by twofold (adjusted OR 2.34, 95\% CI 1.603.09). In these studies, the diagnosis of SDB was made by questionnaires in three and by PSG in the remaining $\mathrm{two}^{21}$. In a largest cohort study with PSG-confirmed SDB $(n=791)$, it was observed that women with SDB had an increased risk of developing preeclampsia (OR 1.6, 95\% CI 2.16-11.26 ${ }^{27}$. This study however did not include the body mass index data and the role of obesity in the findings could not be determined. Louis et $\mathrm{al}^{28}$. in a cohort of 57 women found a significantly higher rate of preeclampsia in SDB compared to normal-weight controls, but the difference ceased to be significant when obese controls were used, defining the independent role of obesity.

The next important point of consideration is that since both SDB and preeclampsia are linked with ED, does $\mathrm{SDB}$ contribute to $\mathrm{ED}$ seen in preeclampsia. In a study conducted by Yinon et $\mathrm{al}^{29}$. in 17 women with preeclampsia and 25 controls with normal pregnancy who underwent ambulatory sleep study and reactive hyperemia test using Endo_Pat, it was seen that the women with preeclampsia had a significantly higher respiratory distress index (RDI; $18.8 \pm 8.4$ vs. $8.3 \pm 1.3$ ) and significantly lower endothelial function index (EFI; $1.5 \pm 0.1$ vs. $1.8 \pm 0.1)$, signifying ED.EFI correlated with RDI and respiratory disturbances contributed to functional abnormality of blood vessels in preeclampsia. More studies are required in this area to determine the role of ED in SDB in the causation of pregnancy-induced hypertension.

Even though there is some evidence regarding the poor maternal and fetal outcomes of SDB during pregnancy, the outcomes of SDB in women with preeclampsia have not been studied extensively. However, preliminary evidence shows a worsening of hypertension as the severity of SDB increases.Yinonet $\mathrm{al}^{29}$. in a study on 17 women with preeclampsia and 25 controls observed that there was a significant correlation between RDI and mean BP $(r=0.41, p<0.05)^{29}$. Also, 
the birthweight of the neonates correlated negatively with RDI $(r=" 0.19, p<0.2)$.

The standard treatment for OSA is the use of nasal continuous-positive airway pressure (CPAP). In a study conducted by Edwards et al ${ }^{30}$. whorecruited patients with severe preeclampsia and did a baseline PSG with continuous BP measurements and repeated the PSG with CPAP, it was observed that there was a significant drop in both the systolic $(p<0.006)$ and diastolic $(p<0.004)$ blood pressure during treatment with $\mathrm{CPAP}^{30}$. In another studyon 24 patients with preeclampsia and 15 controls at 34 weeks' gestation, patients with preeclampsia were randomized to CPAP or no-CPAPand baseline night and intervention night PSG was carried out ${ }^{31}$. Beat-to-beat $\mathrm{BP}$ andstroke volume (SV), heart rate (HR), cardiac output (CO), and systemic vascular resistance(SVR) measurement using photoplethysmography was recorded. It was seen that the $\mathrm{CO}$ increased and the mean arterial pressure (MAP) decreased significantly on the CPAP intervention night.

Guilleminaultet $\mathrm{al}^{32}$. studied 12 patients with risk factors (7 chronic hypertension, 3 obese, 2 prior preeclampsia). At the first prenatal visit, a baseline PSG was conducted and CPAP therapywas started for all patients with flow limitation. It was observed that in the seven patients with chronic hypertension, no titration of anti-hypertensives was required during the course of pregnancy since their BP remained stable;no patient developed preeclampsia and all the women delivered babies with normal weights.

Poyares et $\mathrm{al}^{33}$. also found significantly lower systolic and diastolic blood pressures ( $p<0.0003$ and 0.002$)$ in the pregnant women with chronic hypertension and snoring who were randomized to the CPAP group compared to the controls who were treated with the usual standard care.

Besides an improvement in maternal outcomes, using CPAP, there is some preliminary evidence about improved fetal outcomes in women with preeclampsia. Blytonet $\mathrm{al}^{34}$. found that CPAP treatment increased number of fetal movements and hiccups $(p<00.0001$ and 0.0002 , respectively). They concluded thatthe effectiveness of CPAP in improving fetal movements suggests a pathogenic role for SDB in the reduced fetal activity and possibly poorer fetal outcomes in preeclampsia.
It is concluded thereforethat there is a strong association between preeclampsia and SDB; however the exact causal relationship is yet to be determined. In favor of SDB leading to preeclampsia, it can be said that SDB has many metabolic and cardiovascular outcomes with similar risk factors as preeclampsia. However, the points in favor of preeclampsia leading to SDB are the physiological changes in the upper airway, which are specially pronounced in preeclampsia. More interventional studies with larger number of patients will help in determining the directionality of the association and are urgently warranted.

\section{References}

1. Granger JP, Alexander BT, Llinas MT, Bennett WA, Khalil RA. Pathophysiology of pre-eclampsia: linking placental ischemia/hypoxia with microvascular dysfunction. Microcirculation 2002;9:147-60.

2. American College of Obstetricians and Gynecologists; Task Force on Hypertension in Pregnancy. Hypertension in pregnancy; Report of the American College of Obstetricians and Gynaecologists' Task Force on Hypertension in Pregnancy. ObstetGynaecol 2013; 122:1122.

3. Khan KS, Wojdyla D, Say L, Gulmezoglu AM, Van Look PF. WHO analysis of causes of maternal death: a systematic review. Lancet 2006;367(9516):1066-74.

4. Charlton F, Tooher J, Rye KA, Hennessy A. Cardiovascular risk, lipids and pregnancy: preeclampsia and the risk of later life cardiovascular disease.Heart Lung Circ. 2014 Mar;23(3):203-12.

5. Duley L. Pre-eclampsia and the hypertensive disorders of pregnancy. Br Med Bull.2003;67:161-176.

6. Sibai BM, Caritis S, Hauth J. What we have learned about preeclampsia.SeminPerinatol. 2003;27(3):239-46.

7. Powe CE, Levine RJ, Karumanchi SA. Preeclampsia, a disease of the maternal endothelium: the role of antiangiogenic factors and implications for later cardiovascular disease. Circulation $2011 ; 123(24): 2856-69$.

8. Izci B, Lee K. Sleep disturbances during pregnancy. In: Kryger M, Roth T, Dement W, editors. Principles and practice of sleep medicine. 5. Philadelphia: Saunders; 2010.

9. Young T, Skatrud J, Peppard PE. Risk factors for obstructive sleep apnea in adults. JAMA 2004; 291:2013.

10. Newman AB, Nieto FJ, Guidry U, et al. Relation of sleepdisordered breathing to cardiovascular disease risk factors: the Sleep Heart Health Study. Am J Epidemiol. $2001 ; 154(1): 50-9$.

11. Nieto FJ, Young TB, Lind BK, et al. Association of sleepdisordered breathing, sleep apnea, and hypertension in a large community-based study. Sleep Heart Health Study. JAMA 2000;283(14):1829-36.

12. Peppard PE, Young T, Palta M, Skatrud J. Prospective 
study of the association between sleep-disordered breathing and hypertension. N Engl J Med. 2000 May $11 ; 342(19): 1378-84$.

13. Young T, Peppard P. Sleep-disordered breathing and cardiovascular disease: epidemiologic evidence for a relationship. Sleep 2000;23(Suppl 4):S122-6.

14. Young T, Peppard P, Palta $M$, et al. Population-based study of sleep-disordered breathing as a risk factor for hypertension. Arch Intern Med. 1997;157(15):1746-52.

15. Maski KP, Kothare SV. Searching for marker of REM sleep behavior disorder: submentalis muscle EMG amplitude analysis during sleep in patients with narcolepsy/cataplexy. Sleep 2009;32:137.

16. Imadojemu VA, Gleeson K, Gray KS, Sinoway LI, Leuenberger UA.Obstructive apnea during sleep is associated with peripheral vasoconstriction.Am J RespirCrit Care Med 2002;165(1):61-6.

17. Izci B, Vennelle $M$, Liston WA, et al. Sleep-disordered breathing and upper airway size in pregnancy and postpartum. EurRespir J 2006;27:321.

18. Pilkington S, Carli F, Dakin MJ, et al. Increase in Mallampati score during pregnancy. Br J Anaesth. 1995;74:638.

19. Facco FL, Kramer J, Ho KH, et al. Sleep disturbances in pregnancy. ObstetGynecol 2010;115:77.

20. White DP. Pathogenesis of obstructive and central sleep apnea. Am J RespirCrit Care Med. 2005; 172(11):1363-70.

21. Louis JM, Mogos MF, Salemi JL, et al. Obstructive sleep apnea and severe maternal-infant morbidity/mortality in the United States, 1998-2009. Sleep 2014;37:843.

22. Bourjeily G, Raker CA, Chalhoub M, Miller MA. Pregnancy and fetal outcomes of symptoms of sleep-disordered breathing. EurRespir J 2010;36:849.

23. Aggarwal M, Suri JC, Suri S, Sen MK. Maternal and fetal outcomes of sleep disordered breathing in pregnancy. Indian J Sleep Med.2008;3(1):25-9.

24. Suri JC, Sen MK, Suri J, Vaidya S, Adhikari T., Epidemiology of sleep disorders in pregnant subjects: a questionnaire based survey Indian J Sleep Med 2009; 4(3):106-13.

25. Pien GW, Pack Al, Jackson N, et al. Risk factors for sleepdisordered breathing in pregnancy. Thorax 2014;69:371.

26. Franklin KA, Holmgren PA, Jonsson F, Poromaa N, Stenlund $\mathrm{H}$, Svanborg E. Snoring, pregnancy-induced hypertension, and growth retardation of the fetus. Chest $2000 ; 117(1): 137-41$.

27. Chen YH, Kang JH, Lin CC, et al. Obstructive sleep apnea and the risk of adverse pregnancy outcomes. Am J ObstetGynecol 2012;206:136.e1.

28. Louis JM, Auckley D, Sokol RJ, Mercer BM. Maternal and neonatal morbidities associated with obstructive sleep apnea complicating pregnancy. Am J ObstetGynecol 2010;202:261.e1.

29. Yinon D, Lowenstein L, Suraya S, et al. Preeclampsia is associated with sleep-disordered breathing and endothelial dysfunction. EurRespir J. 2006;27:328-33.

30. Edwards N, Blyton DM, Kirjavainen T, Kesby GJ, Sullivan CE. Nasal continuous positive airway pressure reduces sleep-induced blood pressure increments in preeclampsia. Am J RespirCrit Care Med. 2000;162(1):252-7

31. Blyton DM, Sullivan CE, Edwards N. Reduced nocturnal cardiac output associated with preeclampsia is minimized with the use of nocturnal nasal CPAP. Sleep 2004;27:79.

32. Guilleminault C, Palombini L, Poyares D, et al. Preeclampsia and nasal CPAP: part 1. Early intervention with nasal CPAP in pregnant women with risk-factors for preeclampsia: preliminary findings. Sleep Med. 2007;9:9.

33. Poyares D, Guilleminault C,Hachul H,Fujita L,Takaoka S,Tufik S,Sass N. Pre-eclampsia and nasal CPAP: part 2. Hypertension during pregnancy, chronic snoring, and early nasal CPAP intervention. Sleep Med.2007;9(1):15-21.

34. Blyton DM, Skilton MR, Edwards N, Hennessy N, Celermajer DS, Sullivan CE.Treatment of sleep disordered breathing reverses low fetal activity levels in preeclampsia. Sleep 2013;36(1): 15-21. 